\title{
A Rational Continuum: Legal and Cultural Abortion Narratives in Trump's America
}

\section{Eir-Anne Edgar}

\section{(2) OpenEdition \\ Journals}

Electronic version

URL: https://journals.openedition.org/ejas/15902

DOI: 10.4000/ejas.15902

ISSN: 1991-9336

Publisher

European Association for American Studies

\section{Electronic reference}

Eir-Anne Edgar, "A Rational Continuum: Legal and Cultural Abortion Narratives in Trump's America", European journal of American studies [Online], 15-2 | 2020, Online since 06 July 2020, connection on 08 July 2021. URL: http://journals.openedition.org/ejas/15902 ; DOI: https://doi.org/10.4000/ejas.15902

This text was automatically generated on 8 July 2021 .

Creative Commons License 


\title{
A Rational Continuum: Legal and Cultural Abortion Narratives in Trump's America
}

\author{
Eir-Anne Edgar
}

\section{Introduction}

"T.V. is finally getting realistic about depictions of abortions," proclaims BitchMedia. Even morning coffee news stalwart Good Morning America finds that "Hollywood hasn't always done the best job of depicting women grappling with reproductive health care decisions, such as contraception and abortion, but it's gotten better in recent years." Television shows including Scandal, Empire, Shrill, and movies such as Obvious Child are depicting abortion in nuanced tones and as an everyday occurrence, rather than as a back-alley act of desperation caused by irresponsibility and immature behaviors. Even further, Advancing New Standards in Reproductive Health finds that more and more often, abortions are occurring in comedy shows, rather than in the crime and medical dramas that have traditionally been the genre for such depictions. Yes Magazine notes that "since 2016, Planned Parenthood has collaborated with television and film creators to normalize sexual and reproductive health through storytelling," which has resulted in depictions of abortion that are designed to combat misinformation and stereotypes. Why are depictions of abortion in media important? Because they influence sociocultural perceptions of who gets abortions and why.

Prior to the very recent changes in the narratives of televised depictions of abortion, these fictional accounts did not represent the reality of most abortion seekers. In a comprehensive study of televised depictions of abortion from 2005 through 2014, Gretchen Sisson and Katrina Kimport found that

Compared to statistics on real women, characters who obtained abortions were disproportionately white, young, wealthy, and not parenting. Compared to reports on real women's reasons for abortion, immaturity or interference with future opportunities was overrepresented; financial hardship or pregnancy mistiming was 
underrepresented... overrepresented reasons were more often self-focused rather than other-focused, contributing to a perception that abortion is a want rather than a need. (446) the production of abortion stigma and judgments about appropriate restrictions on abortion care" (446). Though fictional, viewers believe onscreen depictions of abortion to be representative of real experience, no matter how fantastical those depictions may be. As Caron Spruch, director of arts and entertainment engagement at Planned Parenthood states, "Film, TV, and video do so much to normalize sexual and reproductive health and erase the shame that often surrounds it. It's one of our most important tools for educating people, especially young people" (qtd. in Davis). The importance of cultural narratives in shaping public opinion cannot be overstated. However, depictions of abortion in television and film are just one form of abortion narrative that is circulated in culture. These stories can be found in popular culture, such as depictions in television and film, in the opinions and decisions of law cases, in political speeches, and in other public forums. Stephen Greenblatt states that culture is "a process of circulation and negotiation... a network of negotiations for the exchange of material goods, ideas and people" (230). Because culture is not a given, a variety of contending narratives about a practice or person can be found at any one time. Müller-Funk asserts that "narrative is a very powerful-maybe even the most powerful-symbolic 'weapon' in structuring a world that is always in the end, a cultural one" (vii). When considering the contentious narratives about abortion in the United States and the ways in which they can and have transformed over time, Pierre Bourdieu's discussion of fields and narratives is useful to consider. As Herman and Vervaeck state, "In Bourdieu's terms, one would say that narratives travel from one field to another, of example, from the journalistic field to the literary field or from religion to law. This traveling goes back and forth, may entail a wide variety of fields, and always involves a transformation of the narrative, which is precisely what give the narrative its own dynamic, interest, and power" (614). As Bourdieu states, these differing narratives contain the interests held by the field that produces them-religion, law, entertainment, etc. That is why, as I will discuss, so many different narratives about abortion can be found in culture at any one time. One major issue with the circulation of different narratives is that they can work to undermine one another.

Cultural narratives also appear in public forums in political addresses or speeches. often, these addresses seem to be informed by legal narratives, especially since they are issued by elected or appointed officials, some of whom are employed in the highest offices. However, analysis finds that political cultural narratives about abortion can be very different from legal narratives. President Donald Trump's 2019 State of the Union Address illustrates the ways in which the GOP's position on abortion has worked to circumscribe the legal narrative of abortion established in landmark cases such as Roe v. Wade (1973), Planned Parenthood v. Casey (1992), and Whole Woman's Health v. Hellerstedt (2016). These cultural narratives threaten to usurp the public's knowledge of legal narratives of abortion.

6 In order to best understand how the contemporary abortion narrative of the GOP is problematic, it is necessary to look back at decisions and opinions of the Court cases, as 
they determine access to abortion. This article will also analyze Trump's position on abortion via the 2019 State of the Union address. While Trump's perspective is merely one of many (and indeed, it is well documented that he has shifted positions over time), as the President, his perspective is incredibly important-particularly when we consider the power he has in appointing Supreme Court justices such as Brett Kavanaugh, who ostensibly share or are representative of his views and have the ability to make changes in federal law, for better or worse. By examining Trump's State of the Union Address, we get a clear view of the way in which it is a cultural interpretation of legal statutes.

7 Three focal points emerge from Trump's brief discussion of abortion in the 2019 State of the Union Address: the creation of state laws that regulate abortion; the construction of a pregnant person as a woman/mother and of the fetus as a child (though this article does not address the issue of trans people and abortion, this topic is generally absent on the national level, especially within political discussions); and the violation of privacy and the right to choice in state-level attempts to prohibit abortion. These three points connect to key aspects of the three major Supreme Court cases that address abortion-state laws (Whole Woman's Health v. Hellerstedt 2016), the conflation of woman as mother and fetus as child (Planned Parenthood v. Casey 1992), and the loss of privacy and choice (Roe v. Wade 1973).

8 This article will analyze the three major Supreme Court cases in relation to the legal rights they grant, as well as the ways in which abortion law has changed over time. This analysis will focus on the decisions and opinions of the Court cases as they determine the ways in which individuals have access to abortion (rather than the details of the cases that were brought to the Supreme Court, which are both interesting and important narratives on their own). Examining the legal narratives that address abortion rights is an important corrective to Trump's cultural narrative of abortionwhich attempts to limit abortion rights via misinformation or misrepresentation.

\section{Roe v. Wade and Privacy}

9 The 1973 case Roe v. Wade was the first Supreme Court case to address abortion access in the United States. In this case, the Court ruled 7-2 that the right to privacy under the Due Process Clause of the $14^{\text {th }}$ Amendment can be extended to a woman's decision to have an abortion, but this right must be balanced against a state's interest in protecting women's health and protecting potential human life. In order to create said balance, the Court tied the regulation of abortion to the third trimester of pregnancy. Importantly, Roe establishes a person's right to "transactional privacy" in seeking out an abortion-meaning that privacy in this case is connected to the patient's right to seek an abortion via a medical provider (Roe). The Roe decision also establishes a trimester timeline to abortion, which limits the right to seek an abortion within the first two trimesters, with the claim that fetus viability in the third trimester corresponds to the State's interested in protecting potential life.

The case claims that Texas statutes improperly invaded the right of pregnant women to terminate pregnancy. This right can be found in the $14^{\text {th }}$ Amendment or within the personal, marital, familial, and sexual privacy said to be protected by the Bill of Rights or its penumbras-this was cited in a range of Sexual Revolution era cases including Griswold v. Connecticut and Eisenstadt v. Baird. Justice Stewart's concurring opinion in Roe 
cites an earlier case, Poe v. Ullman (1961), in which Justice Harlan stated that the Due Process Clause of the $14^{\text {th }}$ Amendment provided liberty in "a rational continuum." Harlan called this a "freedom from all substantial arbitrary impositions and purposeless restraints." Poe v. Ullman (1961) occurred when a married couple and an unmarried woman argued that Connecticut state laws prohibiting the use of contraceptives were a violation of the $14^{\text {th }}$ Amendment. Though the case was dismissed, the language of the dissent had broad influence. The same issues were later heard again under Griswold v. Connecticut (1965).

11 The concept of a "rational continuum" allows for the major cases of the Sexual Revolution (Griswold, Eisenstadt, Loving, Roe) to be grounded within the $14^{\text {th }}$ Amendment. As James Fleming and Linda C. McClain write, liberty as defined by the Court as a rational continuum, rather than an enumerated list, "conceives judgment as a 'rational process' of 'reasoned judgment' rather than a mechanical application of a bright-line formula, and conceives tradition as a 'living thing' rather than a hidebound historical practice" (217). The Court's definition of liberty as a "rational continuum" and the notion of tradition as a living and flexible thing is maintained in later cases that address abortion rights, including Planned Parenthood v. Casey and Whole Woman's Health v. Hellerstedt.

12 Prior to Roe, full privacy rights are imagined in contraceptive decisions that are nongendered insofar as the body of the citizen remained abstract (Nelson 123). For example, Griswold recognized that married couples had the right to make contraceptive decisions. Nevertheless, this right was interred in the married couple, not within the individual. The right to privacy, as stated in the Roe decision, is limited. The Court states that a pregnant woman is not isolated in her privacy-which makes Roe different from earlier cases that addressed marital intimacy, bedroom possession of obscene material, marriage and procreation, and sexual education issues. The Court states that is it reasonable and appropriate for a State to decide that at some point another interest-the health of a mother or the potential of human life-becomes involved in the process. The form of privacy cited in Roe is transactional in nature. In the case's dissent, Rehnquist states: "a transaction resulting in an operation such as this is not 'private' in the ordinary usage of that word. Nor is the privacy that the Court finds here even a distant relative of the freedom from search and seizure protected by the $14^{\text {th }}$ Amendment" (Roe). Rehnquist's note about privacy and its limits is important. Privacy, as imagined here, is a right to self-autonomy, different from the kinds of privacy established in prior cases (such as the right to be removed from public knowledge). As Rehnquist states, Roe created a transactional privacy-a woman's right to consult with a doctor. This "paradox of privacy" situates the doctor's supervision at the center of socalled autonomy. As Deborah Nelson writes,

The extension of the notion of privacy toward individual autonomy culminated in the paradox of Roe $v$. Wade, a decision that marked the Court's greatest expansion of the right and first retraction of it. No longer an issue of the limits of an individual's private sphere of action, the public debate over privacy began to center on what and when a woman was permitted to choose and, less obviously, what a woman was compelled to say in order to enact that choice. Where in earlier cases addressing a right to privacy, the individual had existed in isolation-alone, autonomous, with rights adhered in to his essentially masculine, although presumptively ungendered body-when privacy became an issue of specially women's autonomy, a second individual, became instrumental to female privacy (113). 
13 Furthermore, the Roe case limited the right to seek an abortion within the first two trimesters, stating that fetus viability in the third trimester corresponded to the State's interested in protecting potential life. Significantly, the right to privacy (as granted via Roe) has all but disappeared in the nationwide discussion of abortion, especially within the realm of cultural narratives, such as in Trump's State of the Union Address.

\section{Planned Parenthood v. Casey and Reaffirming Roe}

14 Twenty years after Roe, Planned Parenthood v. Casey (1992) reaffirmed the legal status of Roe, eliminated trimester restrictions with the addition of the concept of viability, and issued limits to the State's interest in protecting "potential life." The case emerged when Pennsylvania amended state abortion law to require informed consent and a 24hour waiting period prior to the procedure. In this case, "informed consent" meant that a minor would be required to have the consent of one parent. It also meant that a married woman seeking an abortion had to indicate that she notified her husband of her intent to seek an abortion. The Supreme Court justices imposed a new standard to determine the validity of laws restricting abortion. The new standard asks whether a state abortion regulation has the purpose or effect of imposing "undue burden," which is defined as "a substantial obstacle in the path of a woman seeking an abortion before the fetus attains viability" (Planned Parenthood). The only provision to fail was the husband notification requirement.

The Court took any deliberation of Roe or the possibility of limiting abortion very seriously. The decision states, "First is a recognition of the right of the woman to choose to have an abortion before viability and to obtain it without undue interference from the State. Before viability, the State's interests are not strong enough to support a prohibition of abortion or the imposition of a substantial obstacle to the woman's effective right to elect the procedure" (Planned Parenthood). The Court also re-examined foundational premises that the Roe case relies on, particularly the Due Process Clause. Quoting from the 1961 Poe Supreme Court case, of which later cases addressing privacy and sexuality such as Griswold v. Connecticut, Loving v. Virginia, and Eisenstadt v. Baird relied upon, the opinion states: "It is a rational continuum which, broadly speaking, includes a freedom from all substantial arbitrary impositions and purposeless restraints" (Planned Parenthood). Therefore, the Court finds that the Constitutional right to personal liberty found within the Due Process clause allows for individuals to seek an abortion, just as it had allowed for married and unmarried individuals to purchase contraception and allowed for interracial marriage, finding that the Constitution limits “a State's right to interfere with a person's most basic decisions about family and parenthood" (Planned Parenthood). The notion of a right to privacy and sexuality, marriage, and family that had been secured through the major Court decisions during the era of the Sexual Revolution were recognized and upheld in this case, over twenty years later.

Importantly, the justices recognized that, under Roe, access to abortion had been a legal right for two decades. In the decision, Justice Sandra Day O'Connor co-authored language that connects the right to seek an abortion to gender equality. The decision states,

for two decades of economic and social developments, people have organized intimate relationships and made choices that define their views of themselves and 
their places in society, in reliance on the availability of abortion in the event that contraception should fail. The ability of women to participate equally in the economic and social life of the Nation has been facilitated by their ability to control their reproductive lives. (Planned Parenthood)

\section{abortion regulations and undue burden. They state:}

Here, we see not only affirmation of the legality of abortion, but also the ways in which the right to seek abortion is connected to issues of equal rights, identity, and privacy.

A major change in the regulation of abortion with the Planned Parenthood case is the Supreme Court's elimination of the trimester regulation of abortion, which the Court saw as "too rigid." Crucially, the Court focused on viability instead. For the Court, "viability marks the earliest point in which the State's interest in fetal life is constitutionally adequate to justify a legislative ban on nontherapeutic abortions" (Planned Parenthood). The Justices note that the timeline for a viable fetus had changed since Roe and would probably continue to change with technological advancescreating potential future issues as prenatal care evolves over time.

Another important aspect of the Planned Parenthood case is the Court's ruling on State

A finding of an undue burden is a shorthand for the conclusion that a state regulation has the purpose or effect of placing a substantial obstacle in the path of a woman seeking an abortion of a nonviable fetus. A statute with this purpose is invalid because the means chosen by the State to further the interest in potential life must be calculated to inform the woman's free choice, not hinder it. And a statute which, while furthering the interest in potential life or some other valid state interest, has the effect of placing a substantial obstacle in the path of a woman's choice cannot be considered a permissible means of serving its legitimate ends. Regardless of whether exceptions are made for particular circumstances, a State may not prohibit any woman from making the ultimate decision to terminate her pregnancy before viability.

Although the Court finds that the State has an interest in protecting "potential life" after the point of viability, this interest is limited. The State cannot create regulations around abortion that create "undue burden"-regulations whose sole role is to slow or stop women from seeking an abortion, or as the decision states, whose sole purpose or effect is to place "a substantial obstacle" in the path of an abortion seeker (Planned Parenthood). The "husband notification" from Casey was found to be an undue burden by the Court, as it would give husbands power over their wives and could even worsen issues of domestic or spousal abuse. The undue burden standard is widely used in Constitutional law-it is a standard created by the Supreme Court that states that a legislature cannot create a law that is too restrictive or burdensome of one's fundamental rights.

\section{Whole Woman's Health v. Hellerstedt (2016) and Undue Burden}

21 In this Supreme Court case, the Court ruled that Texas cannot restrict the delivery of abortion services that would create an undue burden for abortion seekers. The Court found that just because a state cites "women's health" as a justification for abortion regulations does not make those regulations constitutional if the justifications are not based in credible facts. The Texas state regulations in question included the requirement that abortion centers be designed to meet standards for more 
complicated, hospital-level treatments, as well as an "admitting privileges requirement" which stated that doctors in abortion clinics have standing agreements with doctors in nearby hospitals that would allow them to admit abortion patients in the event of complications instead of just admitting through the ER. These restrictions proved to be issues for several different reasons, especially when examined in light of the undue burden standard established in Planned Parenthood v. Casey. The Texas bill is an example of U.S. regulatory law designed to regulate abortion into non-existence, also known as TRAP laws-“"Targeted Regulation of Abortion Providers." Furthermore, the Court found that the state regulations are unnecessary. As Justice Breyer wrote in the opinion, "Doctors would be unable to maintain admitting-privileges or obtain those privileges for the future, because the fact that abortions are so safe meant that providers were unlikely to have any patients to admit" (Hellerstedt). Admitting privileges are conditional on a certain number of admissions per year-women who need to be transferred to the hospital from the abortion clinic. Therefore, if abortion clinics do not have to send patients to the emergency room because of their relative safely, they would not be eligible to receive admitting privileges as the Texas law would require. The relative safety of abortion also eliminates the first requirement-the Supreme Court found that abortion is far safer than other procedures performed in clinics that are not required to meet those standards, such as colonoscopy, liposuction, and other routine procedures.

Hellerstedt is significant because it closely examines proposed state law and applies the standard of undue burden set by Casey-a phrase that had plagued abortion law scholars for almost two decades. Despite Texas' claims that the laws promoted women's health, the Court found that they would not in fact promote women's health. In fact, the Court found that the two provisions would have the prohibited effect of imposing a substantial obstacle for people seeking abortions. Furthermore, as the Center for Reproductive Rights notes, "the undue burden test has features that may advance constitutional jurisprudence around rights other than abortion." Under the strict scrutiny test, issues such as voting rights and state identification laws will need to be settled in courts that assess "how and whether state interests are furthered, instead of deferring to state claims" ("The Undue Burden Standard"). This is just one of many ways that the issues that undergird abortion rights can have wide applications in different legal contexts.

\section{Legal vs. Cultural Narratives of Abortion}

After reviewing the three major Supreme Court cases that address abortion regulation in the United States-Roe v. Wade, Planned Parenthood v. Casey, and Whole Woman's Health $v$. Hellerstedt, this article provides a clear idea about the legal state of abortion. One can also see how the most recent challenges to abortion on the federal level have emerged from state bills or legislation - which have continued to surface since the Hellerstedt case in 2016. However, it is impossible to think about the legal narratives of abortion without also considering the ways in which abortion is culturally encoded, particularly within political discourse.

This examination of cultural narratives of abortion will focus on President Trump's 2019 State of the Union Address. The State of the Union is historically an annual message delivered to a joint session of the United States Congress by the President. The 
Address typically includes discussion of the budget, an economic report, and it allows for the proposal of a legislative agenda as well as national priorities. The Address fulfills the requirements of Article II, Section III of the U.S. Constitution, which asks that the President "give to the Congress Information of the State of the Union and recommend to their Consideration such measures as he shall judge necessary and expedient" (U.S. House of Representatives). Interestingly, the State of the Union Address has changed over time. During the $19^{\text {th }}$ century, it was treated as a "lengthy administrative report," later, under President Woodrow Wilson the Address also served as a platform "to rally support" and with the development of radio and television, the Address came be seen as "a forum for the President to speak directly to the American people" (U.S. House of Representatives). This evolution, from informative budget plan to politically charged platform for rallying support, explains the nature of Trump's very politically charged Address and the ways in which he discusses the topic of abortion.

\section{2019 State of the Union Address}

Trump's anti-abortion stance is not new for the conservative GOP. It is simply the most recent iteration of what Lauren Berlant refers to as the construction of the fetus as "ideal citizenship" (87). The discourse of reproduction in the United States since the "Reaganite right in the 1970's" has cast "the fetus as a complete and perfect thing and/ or a violently partial thing, somehow ripped away from the mother's body that should have completed it" which has "unsettled the traditional privacy protections" and generated a "normative image of ideal citizenship...of which the fetus is the most perfect unbroken example" (Berlant 86-87). Trump then, is playing on conservative political and religious nostalgia for the Reagan era, as he did when he chose to use Reagan's 1980 slogan, "Let's Make America Great Again" (Pressman). However, Trump has extended Reagan era restrictions. As Daniel Grossman writes, Trump has expanded restrictions against abortion, such as the Global Gag Rule that bans "foreign nongovernmental organizations that receive US funding from using any of their financial resources, regardless of source, to provide, inform about or advocate for access to abortion care in their countries" (89). Trump's fortification of Regan-era restrictions against abortion is a deliberate appeal to an Evangelical base of voters. Despite Trump's personal life (three wives, many affairs and accused assaults, not to mention the many political conspiracies), Evangelicals strongly backed him in 2016 (with $80 \%$ of the white evangelical vote) and will most likely do so again in 2020 (Butler). Gerardo Marti explains Evangelical support of Trump, stating:

White Evangelicals neither obscure nor ignore their religious convictions when they declare their allegiance to the $45^{\text {th }}$ president. In fact, their actions indicate a preeminent concern with upholding orthodoxy. In the case of President Trump, observers should focus on discerning the orthodoxy of an actor who is perceived as religiously legitimate primarily because he engages in actions in support of religiously defined group interests rather than as a result of statements of belief or piety of behavior. (2)

Whether Trump truly believes his message about abortion is unimportant. As President of the United States, he has the power to alter the composition of the Supreme Court as well as make various federal level judicial appointments. Trump's discussion of 
abortion in the State of the Union Address quickly reveals not only his position on third term abortion, but, on the regulation of all abortion.

Trump begins the Address by stating, "The agenda I will lay out this evening is not a Republican agenda or a Democrat agenda. It is the agenda of the American people." Ostensibly, this statement signifies that the Address will not be partisan but will instead more closely resemble the neutral budget agenda of State of the Union Addresses of the past. However, close examination of just one topic-abortion-reveals that the Address contains culturally and politically charged language. The State of the Union contains only a small section that discusses abortion. This discussion is sandwiched between mention of a "plan for nationwide paid family leave" and the U.S. security budget. Trump states:

I am also proud to be the first President to include in my budget a plan for nationwide paid family leave-so that every new parent has the chance to bond with their newborn child. There could be no greater contrast to the beautiful image of a mother holding her infant child than the chilling displays our Nation saw in recent days. Lawmakers in New York cheered with delight upon the passage of legislation that would allow a baby to be ripped from the mother's womb moments before birth. These are living, feeling, beautiful babies who will never get the chance to share their love and dreams with the world. And then, we had the case of the Governor of Virginia where he basically stated he would execute a baby after birth. To defend the dignity of every person, I am asking the Congress to pass legislation to prohibit the late-term abortion of children who can feel pain in the mother's womb. Let us work together to build a culture that cherishes innocent life. And let us reaffirm a fundamental truth: all children -- born and unborn -- are made in the holy image of God. The final part of my agenda is to protect America's National Security.

Placing abortion between family leave and the national security budget makes the issue seem timely and pressing. Despite Trump's statements above, little has changed in federal abortion law-which ultimately regulates access to abortion in the United States. However, the changes that Trump mentions in New York and Virginia are connected to an increase of bills and laws on the state level in regulating abortion. These state level proposals have little to no effect on the regulation of abortion, since abortion is regulated federally via the Supreme Court through cases such as Hellerstedt, Planned Parenthood, and Roe. However, many states have made changes in the case that the Supreme Court might overturn Roe, which would shift abortion to regulation on the state level. And, in many conservative states, if this were to happen, abortion would quickly be outlawed. Furthermore, given the more conservative make-up of the Supreme Court with the addition of Brett Kavanaugh, some states are hoping that their so-called heartbeat bills (which would effectively ban abortion as soon as a fetal heartbeat can be detected-as early as six weeks in some cases) could erode or even challenge Roe on the federal level. At this moment in time, all attempts to issue state abortion restrictions have been blocked or overturned.

On the other side of the abortion debate and in the instituting of state laws, in the State of the Union Address, Trump is referring to the state of New York's Reproductive Health Act and to Virginia's similar bill. Trump's description of the law and bill in New York and Virginia is inaccurate. The Reproductive Health Act allows "a woman to get an abortion after 24 weeks if her health is threatened, not just her life, and if the fetus would be unable to survive outside the womb" (Reilly). The proposed bill in Virginia, struck down by the Virginia House of Delegates, would have similarly allowed for 
abortions in the third trimester for "a fetus that is not viable" outside the womb ("Virginia Late Term Abortion"). However, a close reading of Trump's address suggests that healthy, happy babies would be executed shortly after birth-which neither New York nor Virginia's bill proposed. The interchangeable use of terms including "baby" "person" and "children" in the Address is deliberate-this reflects the Christian Evangelical perspective that all abortion is murder and that the termination of a fetus metonymically equates to the murder of a child or person in the world. The reality of a late term abortion is far more complicated and heartbreaking for the individuals involved than Trump's address suggests. As one woman's story in "Abortion in the Third Trimester" reveals, third trimester abortions are quite rare and are heartbreaking. The woman and her husband were "preparing to welcome a daughter, when she and her husband were given horrible news: A critical piece of the brain had not developed properly." Though the stories of third trimester abortion seekers are not often heard, it is important to contrast the details from this NPR story with the narrative that Trump creates in the Address. Not "ripped from the womb," but third term abortions are rather a series of long and difficult decisions between family members and medical providers.

Indeed, the rarity of the third trimester abortion and the difficulties involved in getting one seem to indicate that this issue-third trimester abortion-is not the real issue that Trump wishes to act on. Instead, Trump wishes to eradicate all abortion, especially if it means that he will be appealing to the Christian Evangelical voters that he signals to in the dog whistle line of the Address that states, "all children-born and unborn-are made in the holy image of God." A Vox article noting Trump's abortion comments in the State of the Union Address were "uncharacteristically extensive comments on the subject," and that they "may be a preview of a more aggressive stance on the issue in the run-up to 2020" (North). The perspective that Trump's abortion comments are connected to voter appeal makes far more sense than the idea that he actually believes that he can create "a culture that cherishes innocent life," particularly when those comments are followed up by a long and detailed justification for the escalation of military spending.

\section{Conclusions}

31 In thinking about abortion in Trump's address, three points emerge: 1 . State abortion laws (which are addressed by the Hellerstedt case); 2. The conflation of woman as mother and fetus as child (connecting to the issue of viability in Planned Parenthood); and 3. the loss of privacy or right to choice for pregnant individuals (privacy that is addressed in Roe and reaffirmed in Planned Parenthood). These three points are embedded within the conservative perspective on abortion-one that supports the creation of state abortion regulations, but only when they impede access, one that views all wombs as biopolitical spaces subject to State regulation, and one that views all fetal life as citizenry that needs to be protected. While there is also language in Trump's address that serves as a dogwhistle for Evangelicals and may be merely connected to concerns with appeal in the 2020 elections, the Address presents cultural narratives about abortion that twist, or even worse, eradicate legal rights.

It is important to analyze cultural narratives about abortion, especially those that are issued from the White House that are presented as being part of a neutral, nonpartisan 
agenda, because they threaten to circumscribe legal narratives. Significantly, the erasure of the right to privacy (however limited) established in Roe signals a distressing trend, one that can be qualified as a general loss of self-determination over one's body, which can be found in similar conservative pushback against transpeople. An underlying thread in Trump's statements in the Address is that individuals are urged to consider the "biological" imperative-as it is linked to Christian Evangelical perceptions of God or religious authority. Under that aegis, a pregnant person is destined to become the "loving mother" of Trump's Address. As further attempts to regulate abortion into oblivion occur on the State level, it is my hope that we do not lose track of the legal narratives that underpin the cultural conversations about abortion.

\section{BIBLIOGRAPHY}

"Abortion in the Third Trimester: A Rare Decision Now in the Political Spotlight," NPR, 30 Apr 2019, accessed 1 Aug 2019. https://www.npr.org/2019/04/30/718546468/opponents-fightefforts-to-protect-late-term-abortion-rights

"Abortion Onscreen in 2018 Portrayals of Abortion on American Television." ANSIRH. 15 Aug 2019, accessed 20 Aug 2019. http://www.ansirh.org/sites/default/files/publications/files/ abortion_onscreen_2018.pdf.

Berlant, Lauren. The Queen of America Goes to Washington City. Duke UP, 1997.

Butler, Athena. “White Evangelicals Love Trump and Aren't Confused About Why. No One Should Be.” NBC News. 27 Sep 2019, accessed 7 Oct 2019. https://www.nbcnews.com/think/opinion/ white-evangelicals-love-trump-arent-confused-about-why-ncna1046826

Davis, Jonita. "Why We're Seeing More Realistic Depictions of Abortion in Television and Film." Yes Magazine. 2 Mar 2018, accessed 30 July 2019. https://www.yesmagazine.org/peace-justice/ planned-parenthood-reproductive-health-abortion-television-film-20190328

Dionne, Evette. "7 Progressive TV Shows that Accurately Depict Abortion." BitchMedia. January 2019, accessed 15 August 2019. https://www.bitchmedia.org/article/how-television-depictsabortion

Fisher, Luchina and Lesley Messer. "How the Portrayal of Abortion in TV and Film has Shifted Since 1928." Good Morning America, Oct 2018, accessed 1 August 2019. https:// www.goodmorningamerica.com/culture/story/portrayal-abortion-tv-film-shifted-1928-58234491

Fleming, James E. and Linda C. McClain. Ordered Liberty: Rights, Responsibilities, and Virtues. Harvard UP, 2013.

Greenblatt, Stephen. "Culture." Critical Terms for Literary Study, edited by Frank Lentricchia and Thomas McLaughlin, University of Chicago Press, 1995.

Grossman, Daniel. "Sexual and Reproductive Health Under the Trump Presidency: Policy Change Threatens Women in the USA and Worldwide." Family Planning and Reproductive Health Care, vol. 43, 2017, pp. 89-91. 
Herman, Luc and Bart Vervaeck. “A Theory of Narrative in Culture." Poetics Today, vol. 38, no. 4, 2017, pp. 605-634.

Marti, Gerardo. "The Unexpected Orthodoxy of Donald J. Trump: White Evangelical Support for the $45^{\text {th }}$ President of the United States." Sociology of Religion: A Quarterly Review, vol. 80, no. 1, 2019, pp. 1-8.

Müller-Funk, Wolfgang. The Architecture of Modern Culture: Towards a Narrative Theory, De Gruyter, 2012.

Nelson, Deborah. Pursuing Privacy in Cold War America. Columbia UP, 2001.

North, Anna. "Why Trump Spent So Much Time Criticizing Abortion During the State of the Union," Vox. 6 Feb 2019, accessed 1 Aug 2019. https://www.vox.com/policy-and-politics/ 2019/2/5/18212521/state-of-the-union-trump-abortion-northam

Pressman, Matthew. “Donald Trump is Reagan's Heir," The Atlantic. 16 Sep 2015, accessed 1 Aug 2019. https://www.theatlantic.com/politics/archive/2015/09/donald-trump-is-reagans-heir/ 405484/

Reilly, Katie. “A New York Law Has Catapulted Later Abortion Back into the Political Spotlight. Here's What the Legislation Actually Does," Time Magazine. 1 Feb 2019, accessed 1 August 2019. https://time.com/5514644/later-abortion-new-york-law/

Sisson, Gretchen and Katrina Kimport. "Facts and Fictions: Characters Seeking Abortion on American Television, 2005-2014." Contraception, vol. 93, 2016, pp. 446-451.

"State of the Union Address." History, Art \& Archives United States House of Representatives. 1 March 2019, accessed 15 Aug 2019. https://history.house.gov/Institution/SOTU/State-of-the-Union/

Trump, Donald. "Read the Full Transcript of President Trump's State of the Union Address," Time Magazine. 6 Feb 2019, accessed 1 March 2019. https://time.com/5521860/2019-state-of-the-uniontrump-transcript/

“The Undue Burden Standard After Whole Women's Health v. Hellerstedt." Center for Reproductive Rights. 1 March 2019, accessed 15 Aug 2019. https://www.reproductiverights.org/sites/ crr.civicactions.net/files/documents/WWH-Undue-Burden-Report.pdf.

United States, Supreme Court. Planned Parenthood v. Casey. 29 June 1992. Legal Information Institute, Cornell U Law School, accessed 1 August 2019. https://www.law.cornell.edu/supremecourt/text/ $505 / 833$

United States, Supreme Court. Poe v. Ullman. 19 June 1961. Legal Information Institute, Cornell U Law School, accessed 1 March 2019. https://www.law.cornell.edu/supremecourt/text/367/497

United States, Supreme Court. Roe v. Wade. 22 January 1973. Legal Information Institute, Cornell U Law School, accessed 1 March 2019. https://www.law.cornell.edu/supremecourt/text/410/113 United States, Supreme Court. Whole Woman's Health v. Hellerstedt. 27 June 2016. Legal Information Institute, Cornell U Law School, accessed 1 March 2019. https://www.law.cornell.edu / supremecourt/text/15-274

"Virginia Late Term Abortion Bill Labeled “Infanticide," BBC News. 31 Jan 2019, accessed 1 March 2019. https://www.bbc.com/news/world-us-canada-47066307 


\section{ABSTRACTS}

Since Trump has taken office, the right to abortion is under threat. The composition of the Supreme Court can change quickly, giving the President opportunity to appoint justices he views as like-minded. This article examines Trump's 2019 State of the Union address and the antiabortion sentiments contained within in conjunction with the rights to personal privacy and reproductive choice established and maintained by US Supreme Court cases Roe v. Wade (1973), Planned Parenthood v. Casey (1992), and Whole Woman's Health v. Hellerstedt (2016). This article posits that the legal status of abortion on a federal level is resolute, but socio-cultural narratives produced by the evangelical, conservative right threaten to undermine the legitimacy of those rights. Significantly, the attempted erasure of the right to privacy established in Roe signals a distressing trend, one that can be qualified as a general loss of self-determination over one's body.

\section{INDEX}

Keywords: abortion, abortion law, US Supreme Court, anti-abortion narrative, biopolitics

\section{AUTHOR}

\section{EIR-ANNE EDGAR}

Eir-Anne Edgar is Associate Professor of Literature in English at ILU, NTNU, Norway. Her research focuses on sexuality and gender in literature and the law. Her work can be found in a range of journals, including the English Journal, Sexuality \& Culture, and Studies in Popular Culture. She has also served as an instructor of Liberal Arts at Interlochen Arts Academy. She completed her PhD in English at the University of Kentucky in 2016. 